\title{
An Arctic Basin Observational Capability using AUVs
}

James G. Bellingham, Knut Streitlien

Massachusetts Institute of Technology $\bullet$ Cambridge, Massachusetts USA

James Overland

Pacific Marine Environmental Laboratory • Seattle, Washington USA

Subramaniam Rajan, Peter Stein Scientific Solutions Inc. • Hollis, New Hampshire USA

John Stannard

Fuel Cell Technologies Ltd. • Kingston, Ontario CANADA

William Kirkwood Monterey Bay Aquarium Research Institute • Moss Landing, California USA

Dana Yoerger

Woods Hole Oceanographic Institution • Woods Hole, Massachusetts USA

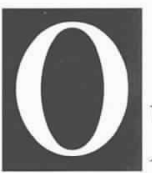

ur goal is to greatly increase access to the Arctic Ocean by creating and demonstrating a safe and economical platform capable of basin-scale surveys. Specifically, we are developing an Autonomous Underwater Vehicle (AUV) for Arctic research with unprecedented endurance and the capability to relay data through the ice to satellites. We will provide a means of monitoring changes taking place in the Arctic Ocean and investigate their impact on global warming. The vehicle will also be capable of seafloor surveys throughout the Arctic basin. We call the vehicle the ALTEX AUV (Figure 1), for the Altantic Layer Tracking Experiment that motivates its development.

The Arctic Ocean poses unique challenges for oceanography because it is, for the most part, covered with sea ice. This makes the Arctic much more difficult to observe as the most widely used observational techniques today are either ship or satellite based. Much of our understanding of the Arctic Ocean comes from the use of nuclear submarines as research platforms. These submarines are active U.S. Naval vessels, and access to them has been provided via a highly successful multiagency agreement called the SCICEX (Scientific Ice Expeditions) program. There are, however, some limitations to the use of such a platform for oceanography:

- The unclassified depth rating of the SSN 637
(Sturgeon class) submarines available to the scientific community is 800 feet, this does not allow characterization of the entire water column.

- Nuclear submarines are expensive to maintain and operate.

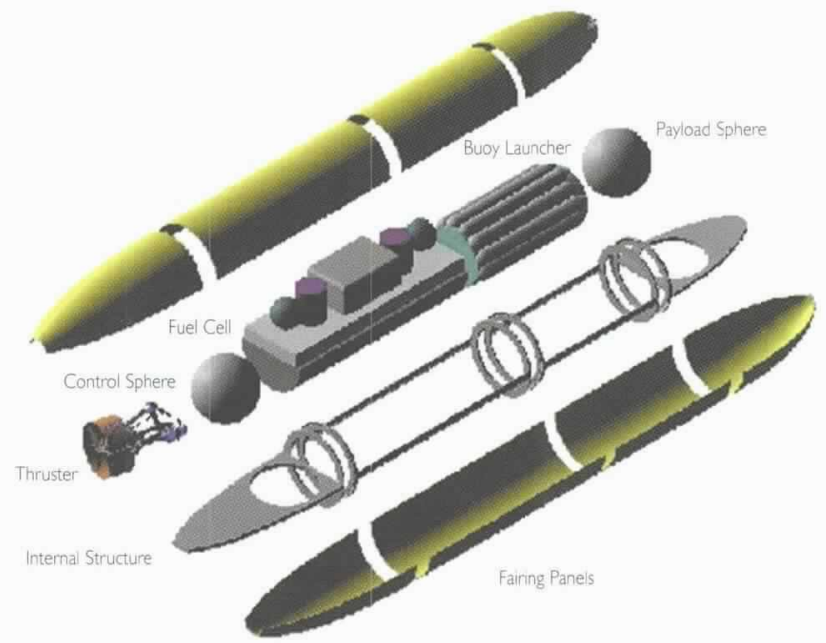

Figure 1: Exploded view of ALTEX Autonomous Underwater Vehicle. The bow section at the far right is available for payloads. The center sections carry the communication buoys and the fuel cell. The stern section contains vehicle propulsion, navigation, and control systems. 
- Measurements near bottom can be carried out in a relatively small portion of the Arctic basin, limited by the submarine's depth rating at the lower extreme, and by dangers of operating under ice at the shallow extreme.

- The ice-capable Sturgeon class submarines are likely to be unavailable soon, potentially ending the SCICEX program.

AUVs have been employed for Arctic science since the 1970s, however operations are typically limited to excursions from ice holes on the order of kilometers (Nodland, 1976; Light and Morrison, 1989; Bellingham and Leonard, 1994). Perhaps the longest under-ice run has been achieved in the deployment of a fiber optic cable from Ellesmere Island to an ice camp $175 \mathrm{~km}$ offshore by a very large AUV (Butler and Black, 1997). All of these operations were shallow, never exceeding depths of a few hundred meters. In contrast, for AUVs to address the large scale climate issues of the Arctic basin, ranges on the order of a $1000 \mathrm{~km}$ and depths of $1500 \mathrm{~m}$ must be achieved. The ALTEX AUV will exceed these goals.

We propose to obtain critical observations on the fate of Atlantic water as it penetrates the Arctic basin, and in so doing, demonstrate a powerful new AUV survey capability for Arctic oceanography. Our science objectives are motivated by the need to understand heat exchange between the Arctic basin and other ocean basins, and in many respect are the logical follow-on to Surface Heat Budget of the Arctic Ocean (SHEBA) program, which examined heat flux between the Arctic ocean and air mass. Our technological objectives are motivated by the general need to develop economic access to the Arctic ocean, although added urgency is lent by the imminent termination of the highly successful SCICEX cruises. The technology which makes this possible, a new long-range AUV, is being developed under a National Ocean Partnership Program (NOPP) effort, which started in June 1998.

\section{Arctic Hydrography and Global Climate}

Recent SCICEX cruises have returned evidence that the Arctic is in the midst of a significant change involving both the atmosphere and the ocean. This is indicated by the increased coverage of the warmer Atlantic water that has been observed in recent years. Data collected during the cruises of the USS Pargo (Morrison et al., 1998) and the Henry Larsen (Carmack et al., 1995; McLaughlin et al., 1996) and the Summer 1994 Arctic Ocean Section of the Polar Sea and the Louis St. Laurent (Carmack et al., 1996) all indicate that the boundary between the eastern and western halocline types now lies roughly parallel to the Mendeleyev Ridge. In terms of longitudinal coverage, this means the area occupied



Figure 2: Contours of the difference in temperature between the $1993 \mathrm{SCI}$ CEX cruise (Morison et al., 1998) and (minus) the temperature from the Joint U.S.-Russian Atlas (EWG, 1997) interpolated to the SCICEX'93 cruise track. For reference: the Mendeleyev Ridge is visible just beyond the Makarov Basin, which is in turn beyond the Lomonosov Ridge.

by the eastern water types is nearly $20 \%$ greater than previously observed.

The greater intensity of the Atlantic influence is also manifested in the warm cores observed over the Lomonosov and Mendeleyev ridges in the Pargo and St. Laurent data, with temperatures over the Lomonosov Ridge greater than $1.5^{\circ} \mathrm{C}$. Figure 2 is a contour plot of the difference between the temperature observed in the 1993 SCICEX experiment and the temperature from the Joint U.S.-Russian Atlas (Environmental Working Group, 1997). The warming of the Atlantic layer is clearly evident from this figure. The historical data of Gorshkov (1983) and Treshnikov (1977) give no indication of such warm cores and show a temperature over the Lomonosov Ridge nearly $1^{\circ} \mathrm{C}$ colder. The recently prepared digital atlas of Russian hydrographic data (Environmental Working Group, 1997) confirms that no temperatures greater than $1^{\circ} \mathrm{C}$ were observed during numerous investigations between 1950 and 1989. The warming of the Atlantic layer has also been reported by other investigators: Carmack et al. (1995), McLaughlin et al. (1996), Mikhalevsky et al. (1995), and Mikhalevsky et al. (1996).

These observed differences represent a fundamental change in the Arctic and it is of utmost importance that these changes in the Arctic Ocean be studied in detail. While we understand the difficulty in distinguishing between anthropogenic climate change and other natural variability, climate models are nearly unanimous in predicting amplified polar response to greenhouse warming (e.g. Manabe and Stouffer, 1994) although models tend to have the warming in winter while recent data show warming (ice reduction) in spring and summer. The connection between lower atmospheric pressure in the Arctic and incursion of warm Atlantic water into the Makarov Basin may indicate an important link in how the climate system manifests polar amplification. 
The water masses of the Arctic Ocean are conditioned by the inflow of the warm Atlantic waters through the Fram Strait, and the inflow of relatively cold water from the Barent Sea. The inflow of the Barents Sea water occurs through the St. Anna Trough. Steele and Boyd (1998) implicate the flow from the Barents Sea in the retreat of the cold halocline laver in the Eurasian basin. This retreat allowed greater heat flux from the Atlantic laver into the upper layers. Computer model studies performed by Zhang et al. (1998) show that after 1989 warming and salinification of the upper Arctic ocean occurs due to a sustained increase of Atlantic flow through the Fram strait, and most significantly, via Barents Sea.

The temperature and salinity changes observed between 1991, 1994 and 1996 are consistent with a warming of the Fram Strait Atlantic inflow. More observations in different years are needed to understand the salt and heat transport in this important area. Observations in the next years may be particularly important in view of the changes observed in the Atlantic Oscillation (AO), which has had a persistent positive phase through the 1990s. Data from the spring of 1999 shows a major reversal to the phase of the $\mathrm{AO}$ with a major increase in sea level pressure. A 16 millibar positive anomaly in the sea level pressure was observed over the Kara Sea in March of 1999. These observations point to the urgent need to conduct experiments to study the changes taking place in the Arctic.

These findings of the changes taking place in the Arctic have generated great interest because of their broad implications and their relation to changes at lower latitudes. Examining the evolution of the variations over time will tell us about the global interaction of Arctic climatic events. This study warrants a multifaceted approach of measurements, observation, data analysis, and modeling. The need is to make repeated hydrographic measurements over the entire Arctic basin.

\section{The Atlantic Layer Tracking Experiment (ALTEX)}

Both the intrusion of the warm Atlantic water in to the Arctic Ocean through the Fram Strait and the inflow of the Barents Sea water contribute to the circulation pattern in the basin which in turn impacts the changes taking place in the Arctic. An investigation of the transport of heat and salt is needed to understand the role of the Atlantic water in the Arctic ocean on the global climate. The Altantic Layer Tracking Experiment is designed to employ the capabilities of the AUV under development to help determine the fate of the Atlantic water advected into the Arctic basin.

A surface mixed layer is present in the entire central Arctic basin. While its salinity and thickness vary from region to region, its temperature is reasonably constant and is close to freezing. Measurements of temperature and salinity structure in the western Nansen Basin by Schauer et al. (1997) show the existence of a warm layer beneath the surface mixed laver. The presence of water with high temperatures (higher than $2.5^{\circ} \mathrm{C}$ ) and salinity (greater than $35.0 \mathrm{ppt}$ ) indicate the presence of warm Atlantic water. The Atlantic layer is normally found between the depths of $200 \mathrm{~m}$ to $600 \mathrm{~m}$. The core of the layer (location of temperature maximum) lies about 30$40 \mathrm{~km}$ seaward of the shelf break. The lateral extent of the Atlantic layer varies from region to region.

The temperature of the water decreases monotonically towards the bottom. The measurements by Schauer et al. (1997) also show the presence of relatively cold and low salinity water at depths greater than $500 \mathrm{~m}$. These and other observations suggest intrusion of cold and less saline water at different depths. The major inflow of cold and less saline Atlantic water from the Barents Sea is through the St. Anna Trough (Figure 3). The circulation in this vicinity is likely to be complex. In addition local shelf water plumes leak from the shelf edge to the west Nansen Basin (Schauer et al.,1997).

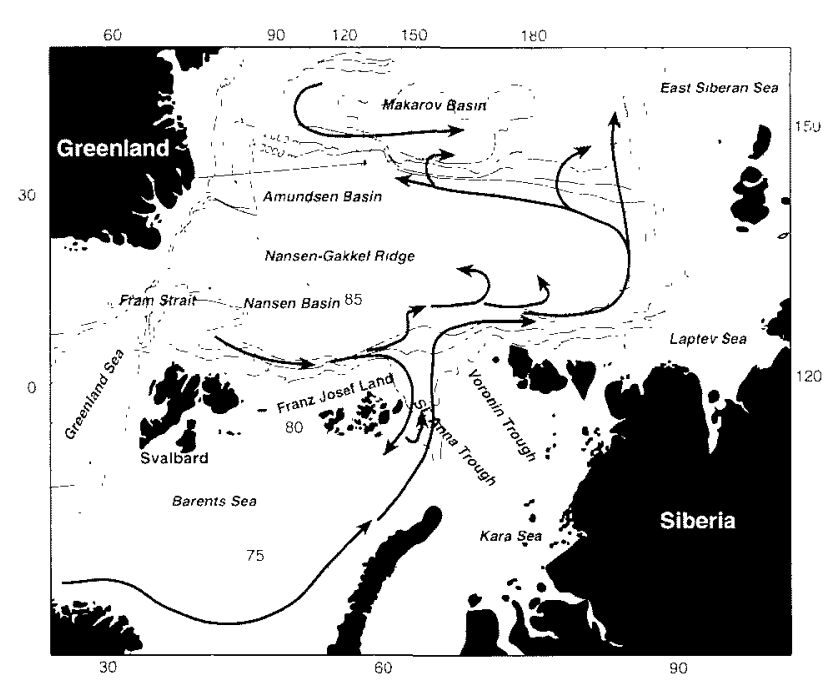

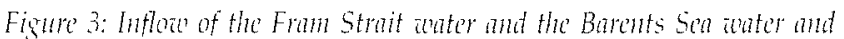
their distribution within the Nanson basin

The objective of the observation program is to measure the temperature $(T(x, y, z))$ and salinity $(S(x, y, z))$ in the critically important region north of Svalbard and Franz Josef Land. Even though the Atlantic layer is expected to lie between $200 \mathrm{~m}$ and $600 \mathrm{~m}$, intrusion of water from other sources penetrates into deeper regions. The sampling is therefore designed to determine the temperature and salinity structure to a depth of $1100 \mathrm{~m}$.

Consistent with these observations the following sampling strategy will be adopted:

- The vehicle will, on launch, descend to a depth of $400 \mathrm{~m}$ and do saw-tooth operation travelling between 200 to $600 \mathrm{~m}$. The temperature and salinity values will be measured every 2 minutes.

- The vehicle will navigate itself vertically, so as to remain within the Atlantic layer, by sensing the 
change in the temperature of the water surrounding the vehicle. The vehicle will additionally stay above the $1300 \mathrm{~m}$ isobath as we believe that the core of the Atlantic layer lies here.

- The vehicle will search for the lateral extent of the Atlantic layer every third day in the North-South direction.

- The vehicle will descend to maximum depth (1100 $\mathrm{m}$ ) once a day and make a measurement of the temperature and salinity.

- Once a day the rehicle will come up to a depth of $50 \mathrm{~m}$ in search of a suitable place for launching the ice-penetrating buoy.

- Upon reaching St. Ann Trough, the vehicle will continue on an eastward trajectory and make N-S excursions.

- At the eastern slope of the trough, the vehicle will head south for recovery

The vehicle flight path is shown in Figure 4.

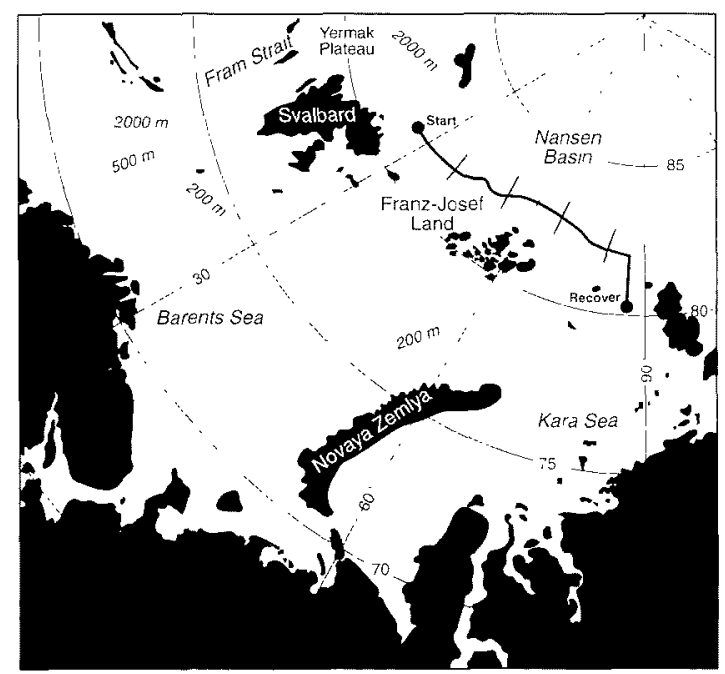

Figure t: Track of andicle for the ALTEX mission.

\section{An AUV for Basin-scale Arctic Surveys}

The design of the ALTEX AUV was guided by a set of needs distilled from both the specifics of the Atlantic Layer Tracking Experiment, and from more general observations of Arctic science. The primary requirement is for an AUV with a range that enables basin scale observations. The vehicle must have at least a $1500 \mathrm{~m}$ depth rating for Arctic hydrography, but ideally should be capable of operating through the entire range of depths of the Arctic basin. Furthermore, the vehicle must be small enough to be logistically manageable, and must be cost effective. Finally, the system must be reconfigurable to satisfy a wide range of science objectives.

The complete ALTEX vehicle is $4.8 \mathrm{~m}$ long and $0.53 \mathrm{~m}$ in diameter. The vehicle's outside diameter conforms to standard U.S. Navy torpedoes. The vehicle is being designed to a $4500 \mathrm{~m}$ depth requirement, except for the communication buoy's, which are rated to $1500 \mathrm{~m}$. A full ALTEX rehicle with a minimal payload has a design range of $1500 \mathrm{~km}$. A vehicle with two semi-fuel cells and no buoy section wrould be capable of a $3000 \mathrm{~km}$ range.

A modular rehicle has been designed that separates components into four functional sections: the forward payload section, the buoy section, the semi-fuel cell section, and the tail section which contains propulsion, guidance, and control systems. Figure 1 shows the major components of the vehicle. The aft section constitutes a complete, self-contained control and propulsion module. All necessary control, navigation, and communications hardware resides in a single $17^{\prime \prime}$ spherical pressure vessel. This includes the main vehicle computer, acoustic and radio frequency modems, and an Inertial Navigation System.

The propulsion and control module is one integral unit, where the ducted propeller and thruster motor move in unison by means of two linear actuators. This compact and robust tailcone is designed to withstand the rigors of extended Arctic deployment, as well as provide outstanding maneuverability and stability. The articulated tailcone design is capable of $+/-20$ degrees motion and is constructed primarily of plastic and aluminum. The tailcone electronics are housed in an oilfilled enclosure, and operate at ambient pressure. Many of the electronic boards and test protocols have been adapted from systems developed for MBARl's Tiburon Remotely Operated Vehicle (ROV).

The main vehicle software architecture has been established, and core elements of the software code created. The vehicle's core software is object-oriented, running under the real-time operating system QNX, on industry-standard PC 104 hardware. A great deal of effort is being made to ensure that the software is robust, expandable, and maintainable for years to come. The Odyssey control architecture (Bellingham and Leonard, 1994) has been ported to the new environment.

The mechanical infrastructure consists of an exoskeletal stressed skin connected by interlocking rings and axially oriented members. This concept results in high structural, packaging, and hydrodynamic efficiency. The skin is made from impact resistant ABS plastic, which makes the vehicle extremely robust in launch, operation, and recovery. The interlocking joining rings are designed to allow rapid assembly and disassembly of the vehicle into its individual modular sections, making the logistics of development, maintenance, and shipping manageable.

Industry standard connections allow the tail section be matched to a number of different power sources and payload packages. The modular vehicle layout allows these sections to be developed and assembled remotely. Distribution of power and data takes place through a backbone of cables in oil filled tubes and junction boxes. This solution was chosen for its high reliability and flexibility. 


\section{Energy Systems for Long Endurance}

One of the outstanding challenges of the project has been the creation of an energy system that will support ranges in excess of $1000 \mathrm{~km}$. The semi-fuel cell developed under this program is innovative in that it is pressure compensated. This provides a number of advantages over more traditional designs that enclose the semi-fuel cell in a pressure housing. The primary payoff is a substantial reduction in the weight of the vehicle, due to the absence of a large, deep-rated pressure housing. Additionally, the system will be safer, as any leaks of the volatile reactants will be vented directly to the water environment, rather than to the electronic-filled interior of a pressure bottle. Finally, the system should be effectively pressure independent, thus providing a powerful new energy source for deep ocean applications. The fuel cell is being designed for a $4500 \mathrm{~m}$ depth capability.

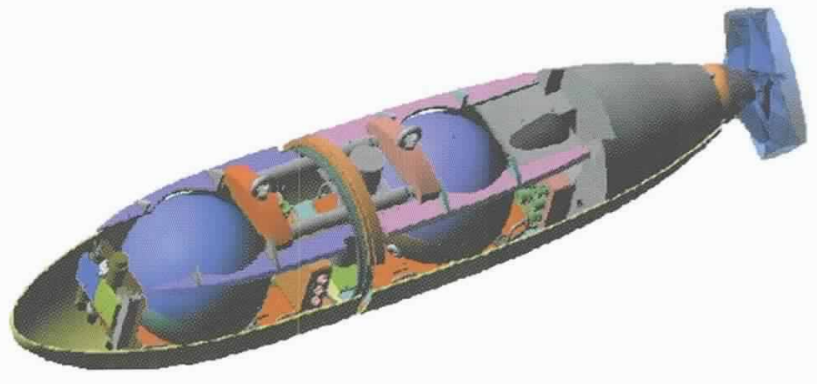

Figure 5: Detail of nose and stern section of ALTEX vehicle. The buoy and fuel cell sections are inserted between these two elements of the vehicle. Alternatively, the bow and stern can make a complete vehicle, if the forward sphere is used for batteries.

The semi-fuel cell vehicle section (Figures 5 and 6) utilizes the high energy density of aluminum, and an oxygen content of $50 \%$ peroxide to produce a depth independent refuelable energy source. Efficient use of reactants is achieved using a two flow-loop system consisting of a $\mathrm{KOH}$ anolyte and a controlled concentration peroxide catholyte. Depth independence is achieved through storage of only solid or liquid reactants and wastes. Highly efficient brushless, armatureless pumps and minimal active controls reduce parasitic power consumption. Energy density for the fuel cell alone based on current tests of full size cells is projected as over 350 (Wh/kg dry weight). The complete system for $66 \mathrm{kWh}$ of net energy, packaged as a neutrally buoyant

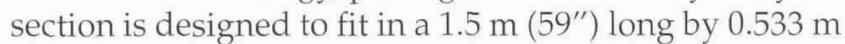
(21") diameter hull section. For the vehicle $66 \mathrm{kWh}$ net will provide propulsion power (150W) and hotel power (100W) for 260 hours.

Fuel cell reactants are stored in two removable flexible storage tanks. Turn around time for a complete refueling is expected to be two hours or less. Liquid reactants are low cost and significant portions of the cell stack will be reusable, keeping total refueling costs low compared to replacement of primary batteries. Depleted cell stacks will be refurbished by the manufacturer, by the addition of new aluminum anodes and replacement of gaskets.

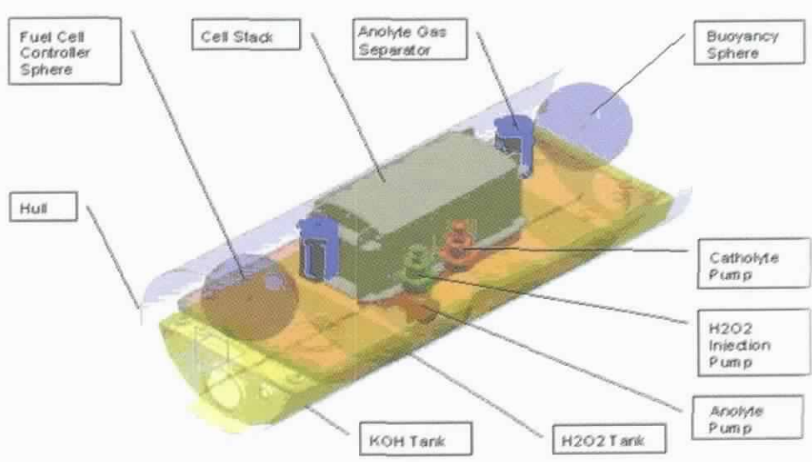

Figure 6: Aluminum / peroxide pressure compensated semi-fuel cell

\section{Navigation}

The vehicle navigation consists of two phases. First, the AUV must perform real-time navigation in order to execute the mission. Second, GPS fixes from the buoys should be be used in post-processing to improve the vehicle position estimates.

Real-time navigation requirements do not require great accuracy for position. The specific track line followed is not crucial, but should be well known after the mission. The scientific survey strategy requires that the vehicle follow a specific bottom contour $(1300 \mathrm{~m})$ with periodic tracks normal to the isobath. While high quality heading information is critical to the mission, the navigation system must provide only sufficient positional accuracy to keep track of progress along the isobath, so the mission can be altered as major alongtrack features are reached.

In real-time, the vehicle will navigate using a combination of an Inertial Navigation System (INS), bottom bathymetry, and an open-loop model of the vehicle's thrust/speed characteristics. An accurate, drift-free heading reference is required to follow an isobath and to return to it after a cross leg. The vehicle control will be dominated by the heading loop, which will be commanded to head along (or across) the isobath in the nominal, a priori direction. The commanded heading will be altered with very low-bandwidth corrections based on the bathymetry. In particular, a good heading estimate is required to avoid a pathological control condition should a closed isobath be encountered (the vehicle would go in circles forever).

We excluded a north-seeking gyro due to their poor performance at high latitude. A commercial fiber-optic north-seeker specifies heading errors at $0.7 x$ secant(lati- 
tude), which means approximately 7 degrees at 84 degrees north. In contrast, a full INS provides a fraction of a degree of heading accuracy. With a solid estimate of true north, we can maintain good control along the isobath as well as during the cross legs.

During the mission, we will process the navigation based on information from the buoys (GPS fixes) as well as some information from the INS obtained through the communications links. After the vehicle is recovered, we will reprocess the navigation using the full INS data set from the vehicle data logger.

\section{Communications}

The ice penetrating buoys are carried by the vehicle in the buoy section and provide a means of both transmitting data from the AUV to shore, and for obtaining GPS position fixes along the vehicle track (Figure 7). The buoys function as follows:

- On release from the vehicle a buoy will ascend to the surface and penetrate through the ice and deploy a GPS antenna and an ARGOS antenna,

- The GPS system will provide the location of the buoy, which will be used later to correct the track of the vehicle in post processing of data.

- The ARGOS antenna will be used to transmit data transferred to the buoy prior to its launch from the vehicle.

- Similar to all other sections of the vehicle, the design of the buoy section is modular to allow complete flexibility of vehicle configuration.

The pre-launch activity of the vehicle consists of uploading the data into the next buoy in the launch sequence and locating a suitable launch site with an ice cover of up to one meter thick. The vehicle then slows to minimum controllable speed (approximately one knot) at a depth of at least 50 meters. The launcher then releases the designated buoy from the AUV. In its launch configuration, the buoy is slightly buoyant to limit its ascent rate to $1 \mathrm{~m} / \mathrm{s}$. The launcher also releases a weight simultaneously with each buoy in order to maintain neutral buoyancy of the vehicle.

Upon its release, the buoy floats towards the surface where it comes to rest against the bottom surface of the ice. Next, the buoy is extended by means of pressurized nitrogen, which increases the separation between its Center of Buoyancy and its Center of Gravity. In this configuration, the buoy becomes stable in an upright orientation. The chemical reaction of seawater with Pyrosolve- $Z$, contained in the nose cone of the buoy, starts the melting process. This reaction generates approximately 1500 watts of power for 30 minutes. Immediately following the termination of the chemical reaction, the nose cone is ejected and the GPS and ARGOS antennae are deployed. After the antenna deployment, the buoy obtains a GPS fix, and initiates its data telemetry via ARGOS. This process continues until the batteries are expended. It is also important to mention that a full set of data can be stored in permanent memory within the buoy's onboard computer. With the knowledge of its GPS position, the buoy can even be recovered for downloading the data.

\section{Status and Future Work}

Development of the ALTEX vehicle is entering its field-testing phase. Laboratory tests of most major elements of the vehicle have been completed, and a phased sequence of sea tests has begun. Milestones achieved thus far include:

- Testing of full size aluminum-peroxide cells has demonstrated the necessary reactant efficiencies. Trial testing at sea in early 2000 will verify system operation and reliability.

- During the Office of Naval Research (ONR) sponsored Applied Physics Laboratory Ice Station (APLIS) in early April 1999, the ability of the buoy to penetrate sea ice was demonstrated.

- The new control and navigation architecture has been demonstrated at sea on an Odyssey IIb vehicle with an ALTEX main vehicle computer and software.

- All major elements of the core vehicle have been fabricated and are being assembled for testing in spring of 2000.

Subsequent tests will successively demonstrate the core vehicle elements, the semi-fuel cell, and the buoy launcher section. The extended nature of AUV operations (in excess of ten days) poses significant logistical demands on full-scale field testing, and creates a high demand for robust AUV systems and software.
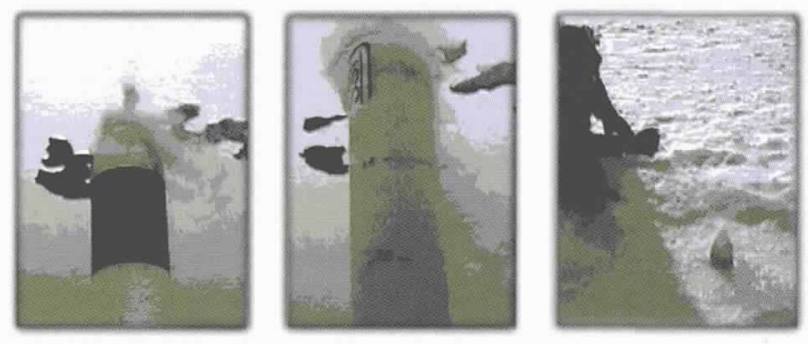

Figure 7: The ice penetrating buoy. At left the buoy begins melting through the ice, as seen from under the ice. The dark traces are gaseous byproducts of the chemical reaction entrapped within the ice-water interface. The plume of smoke is a clear indication of sustained reaction. The middle picture shows the buoy partway into the ice. Note the presence of cross currents as the plume is being carried sideways in the water. At right is a photograph of the buoy at the surface at the end of its melting process.

The first Arctic tests are expected to occur in spring of 2001, and will focus on demonstration of the feasibility of all phases of the AUV operations under circumstances that allow close monitoring of the AUV. The ALTEX mission is scheduled for August of 2002.

Perhaps the most challenging aspect of the ALTEX project was to find a sponsor willing to support such a high-risk, multi-disciplinary venture. In our case, that support has come from the National Ocean Partnership 
Program. The challenges inherent in starting such a project are familiar: the technology is difficult to justify on the basis of a single scientific experiment, yet very few programs have a charter that encourages supporting technology-infrastructure projects, no matter how promising. It is true that the limited period of support for the NOPP (two years at the time the ALTEX program was funded) limits the amount of progress it is possible to make. However, an alternative perspective is to view the NOPP support as "seed money" sufficient to demonstrate the power of both an idea and a team. With results in hand, the search for support from more traditional funding sources while still difficult, is certainly more manageable. For the ALTEX project, continued support will come from both the National Science Foundation (NSF) and ONR.

Thus the NOPP provides an important resource for soliciting and enabling high-risk, high-return projects that would otherwise remain merely good ideas. Given the increasing technological sophistication of oceanography, and the rapid rate of change of many of the underlying technologies, providing a mechanism to encourage technological innovation with resources sufficient for meaningful work should have an impact much larger than the proportion of dollars spent.

\section{Acknowledgements}

The National Ocean Partnership Program was instrumental in providing the funding to initiate this effort, enabling the multi-institutional, multi-disciplinary teaming necessary to achieve critical mass necessary for this complex undertaking. This work has been supported by the National Ocean Partnership Program under contract N00014-98-1-0814, administered by the High Latitude Dynamics Program at the Office of Naval Research. The substantial MBARI participation has been supported by the Packard Foundation. NOAA has supported work through the provision of ship time for system testing. We would like to gratefully acknowledge Tom Curtin of the Office of Naval Research, who inspired the ALTEX program.

\section{REFERENCES}

Bellingham, J.G. and J.J. Leonard, 1994: Task Configuration with Layered Control. In: Mobile Robots for SubSea Environments: IARP 1994, International Advance Robotics Programme, 193-202.

Butler, B., and M.R. Black, 1997: The Theseus Autonomous Underwater Vehicle: Two Successful Missions. In: Unmanned Unethered Submersible Technology, 10th Symposium, 12-22.

Carmack, E.C., R.W. Macdonald, R.G. Perkin, F.A. McLaughlin and R.J. Pearson, 1995: Evidence for Warming of Atlantic Water in the Southern Canadian Basin of the Arctic Ocean: Results from the Larsen-93 Expedition. Geoply. Res. Lett., 22, (9), 1061-1064.

Carmack, E.C., K. Aagaard, J.H. Swift, R.W. Macdonald, F.A. McLaughlin, E.P. Jones, R.G. Perkin, J.N. Smith,
K. Ellis and L. Kilius, 1996: Changes in Temperature and Contaminant Distributions within the Arctic Ocean. Deep Sea Res.

Environmental Working Group, 1997: Joint U.S.-Russian Atlas of the Arctic Ocean, Oceanography Atlas for the Winter Period. In Press, National Ocean Data Center, CD-ROM available from the National Ocean Data Center.

Gorshkov, S.G., 1983: Arctic Ocean. The World Ocean Atlas series, Oxford, Pergamon.

Light, R., and J. Morrison, 1989: The Autonomous Conductivity-Temperature Vehicle: First in the Seashuttle Family of Autonomous Underwater Vehicles for Scientific Payloads. In: Proceetings Oceans '89, 793-798.

Manabe, S., and R.J. Stouffer, 1994: Multiple-Century Response of a Coupled Ocean-Atmosphere Model to an Increase of Atmospheric Carbon Dioxide. I. Climate, 7, 5-23.

McLaughlin, F.A., E.C. Carmack, R.W. McDonald and J.K.B. Bishop, 1996: Physical and Geochemical Properties across the Atlantic/Pacific Water Mass Front in the Southern Canadian Basin. J. of Geophlys. Res., 101 (C1), 1183-1195.

Mikhalevsky, P.N., A. Gavrilov, A.B. Baggeroer and M. Slavinsky, 1995: Experiment Tests Use of Acoustics to Monitor Temperature and Ice in the Arctic Ocean. Eos, Trans. Anl. Goo. Linion, Vol. 76(27), 265-268.

Mikhalevsky, P.N., R.E. Keenan and A.B. Baggeroer, 1996: Measured Transarctic Traveltimes and Model Comparisons. In: Proceedings 3rd European Conference on Acoustics, Vol. 2, 773-777.

Morrison, J., M. Steele, and R. Andersen, 1998: Hydrography of the Upper Arctic Ocean Measured from the Nuclear Submarine USS Pargo. Deep Sea Res., 45, pp. 15-38

Nodland, W.E., 1976: Several Applications of Unmanned, Free-Swimming Submersibles in Oceanographic Research. 4th International Ocean Development Conference, Tokyo, Japan, September 28 - October 1, 1976.

Schauer, U, R.D. Muench, B. Rudels and L. Timokhov, 1997: The Impact of Eastern Arctic Shelf Waters on the Nansen Basin Intermediate Layers. J. Geophys. Res., 102, 3371-3382

Steele, M. and T. Boyd, 1998: Retreat of the Cold Halocline Layer in the Arctic Ocean. J. Geoplyys. Res., 103, 10419-10435.

Treshnikov, A.F., 1977: Water Masses of the Arctic Basin. In: Polar Oceans. Calgary, Arctic Institute of North America. 17-31.

Zhang, J., D.A. Rothrock and M. Steele, 1998: Warming of the Arctic Ocean by a Strengthened Atlantic Inflow: Model Results. Geophys. Res. Lett., 25, 17451748 . 